\title{
How Low should the Blood Pressure be reduced in Patients with Hypertension and High Risk for Coronary Artery Disease?
}

\section{Wilbert S Aronow*}

Department of Medicine, Divisions of Cardiology, Pulmonary/Critical Care, and Geriatrics, Westchester Medical Center/New York Medical College, Valhalla, NY, USA

The more aggressive control of blood pressure among patients at high risk for coronary artery disease such as those with coronary artery disease, a 10 -year Framingham risk score $\geq 10 \%$, diabetes mellitus, chronic kidney disease, or other coronary artery risk equivalent with maintenance of the blood pressure below 130/80 $\mathrm{mm} \mathrm{Hg}$ and below 120/80 $\mathrm{mm} \mathrm{Hg}$ in patients with left ventricular dysfunction recommended by the American Heart Association (AHA) Task Force scientific statement in 2007 [1] was based upon expert medical opinion at that time, not on prospective, randomized, adequately controlled trial data [2].

The Pravastatin or Atorvastatin Evaluation and Infection TherapyThrombolysis in Myocardial Infarction (PROVE IT-TIMI) 22 trial enrolled 4,162 patients with an acute coronary syndrome (acute myocardial infarction with or without ST-segment elevation or highrisk unstable angina pectoris) [3].The lowest incidence of cardiovascular events occurred with a systolic blood pressure between 130 to $140 \mathrm{~mm}$ $\mathrm{Hg}$ and a diastolic blood pressure between 80 to $90 \mathrm{~mm} \mathrm{Hg}$ with a nadir of $136 / 85 \mathrm{~mm}$.

An observational subgroup analysis was performed in 6,400 of the 22, 576 patients in the International Verapamil SR-Trandolapril Study (INVEST) [4]. These patients had diabetes mellitus and coronary artery disease. Patients were considered to have tight control of their blood pressure if they could maintain their systolic blood pressure below $130 \mathrm{~mm} \mathrm{Hg}$ and their diastolic blood pressure below $85 \mathrm{~mm} \mathrm{Hg}$, usual control if they could maintain their systolic blood pressure between 130 to $139 \mathrm{~mm} \mathrm{Hg}$, and uncontrolled if their systolic blood pressure was $140 \mathrm{~mm} \mathrm{Hg}$ or higher.

During 16,893 patient-years of follow-up, the incidence of cardiovascular events was $12.6 \%$ in patients with usual control of blood pressure versus $19.8 \%$ in patients with uncontrolled hypertension, $\mathrm{p}$ $<0.001$ [4]. The incidence of cardiovascular events was $12.6 \%$ in patients with usual control of blood pressure versus $12.7 \%$ in patients with tight control of blood pressure ( $\mathrm{p}$ not significant). The all-cause mortality rate was $11.0 \%$ with tight control of blood pressure versus $10.2 \%$ with usual control of blood pressure $(\mathrm{p}=0.06)$. When extended follow-up was included, the all-cause mortality rate was $22.8 \%$ with tight control of blood pressure versus $21.8 \%$ with usual control of blood pressure, $p$ $=0.04$.

The Action to Control Cardiovascular Risk in Diabetes (ACCORD) blood pressure trial randomized 4,733 patients with type 2 diabetes mellitus to intensive blood pressure control with a target systolic blood pressure of $<120 \mathrm{~mm} \mathrm{Hg}$ or to standard blood pressure control with a target systolic blood pressure $<140 \mathrm{~mm} \mathrm{Hg}$ [5]. The primary composite outcome was nonfatal myocardial infarction, nonfatal stroke, or death from cardiovascular causes. The mean follow-up was 4.7 years. After 1 year, the mean systolic blood pressure was $119.3 \mathrm{~mm} \mathrm{Hg}$ in the intensive blood pressure control group versus $133.5 \mathrm{~mm} \mathrm{Hg}$ in the standard blood pressure control group. The annual rate of the primary outcome was $1.87 \%$ in the intensive blood pressure control group versus $2.09 \%$ in the standard blood pressure control group ( $\mathrm{p}$ not significant). The annual rate of death from any cause was $1.28 \%$ in the intensive blood pressure control group versus $1.19 \%$ in the standard blood pressure control group ( $\mathrm{p}$ not significant).The annual rate of stroke, a prespecified secondary outcome, was $0.32 \%$ in the intensive blood pressure control group versus $0.53 \%$ in the standard blood pressure control group, $\mathrm{p}=$ 0.01 . Serious adverse events attributed to antihypertensive treatment occurred in $3.3 \%$ of the intensive blood pressure control group versus $1.3 \%$ of the standard blood pressure control group $(\mathrm{p}<0.001)$ [5].

On the basis of the available data, the American College of Cardiology Foundation (ACCF)/AHA 2011 expert consensus document on hypertension in the elderly recommended that patients with hypertension younger than 80 years should have their blood pressure reduced to $130-139 / 80-89 \mathrm{~mm} \mathrm{Hg}$ [6]. Based on data from the Hypertension in the Very Elderly Trial (HYVET), [7] patients with hypertension aged 80 years and older should have their systolic blood pressure reduced to $140-145 \mathrm{~mm} \mathrm{Hg}$ if tolerated [6].

We studied the impact of baseline systolic blood pressure on outcomes in 7,785 persons with mild to moderate chronic congestive heart failure in the Digitalis Investigation Group trial [8]. A baseline systolic blood pressure $\leq 120 \mathrm{~mm} \mathrm{Hg}$ was associated during 5 years of follow-up with a $15 \%$ increase in cardiovascular mortality ( $\mathrm{p}$ $=0.032)$, with a $30 \%$ increase in heart failure mortality $(\mathrm{p}=0.006)$, with a $13 \%$ increase in cardiovascular hospitalization $(\mathrm{p}=0.008)$, with a $10 \%$ increase in all-cause hospitalization ( $\mathrm{p}=0.017)$, and with a $21 \%$ increase in heart failure hospitalization $(\mathrm{p}=0.002)$ [8].

In the Ongoing Telmisartan Alone and in Combination With Ramipril Global Endpoint Trial (ONTARGET), a progressive increase in the proportion of visits in which the blood pressure was decreased to $<140 / 90 \mathrm{~mm} \mathrm{Hg}$ or to $<130 / 80 \mathrm{~mm} \mathrm{Hg}$ was associated with a progressive decrease in stroke, new onset of microalbuminuria or macroalbuminuria, and return to normoalbuminuria in persons with albuminuria [9]. However, the adjusted risk of cardiovascular events was reduced by increasing the frequency of blood pressure control to $<140 / 90 \mathrm{~mm} \mathrm{Hg}$ but not to $<130 / 80 \mathrm{~mm} \mathrm{Hg}$ [9].

During $>12$ years of median follow-up in the Cardiovascular Health Study, we found that isolated diastolic hypotension (a diastolic blood pressure $<60 \mathrm{~mm} \mathrm{Hg}$ with a systolic blood pressure $\geq 100 \mathrm{~mm}$ $\mathrm{Hg}$ ) was associated with a $29 \%$ significant independent increase in incident congestive heart failure $(p=0.003)$ [10]. Therefore, isolated

*Corresponding author: Wilbert S. Aronow, Professor of Medicine, Cardiology Division, New York Medical College, Macy Pavilion, Room 138, Valhalla, NY 10595, USA, Tel: 9144935 311; Fax: 9142356 274; E-mail: wsaronow@aol.com

Received March 13, 2012; Accepted March 15, 2012; Published March 18, 2012

Citation: Aronow WS (2012) How Low should the Blood Pressure be reduced in Patients with Hypertension and High Risk for Coronary Artery Disease? J Hypertens 1:e104. doi:10.4172/2167-1095.1000e104

Copyright: ( 2012 Aronow WS. This is an open-access article distributed under the terms of the Creative Commons Attribution License, which permits unrestricted use, distribution, and reproduction in any medium, provided the original author and source are credited. 
Citation: Aronow WS (2012) How Low should the Blood Pressure be reduced in Patients with Hypertension and High Risk for Coronary Artery Disease? J Hypertens 1:e104. doi:10.4172/2167-1095.1000e104

systolic hypertension and isolated diastolic hypotension are significant risk factors for congestive heart failure in community-dwelling older persons.

Until additional data from randomized controlled trials (including the Systolic Blood PRessure INtervention Trial-SPRINT) comparing various blood pressure targets in elderly and younger patients become available, existing epidemiologic and clinical trial data suggest a diagnostic and therapeutic threshold for hypertension of 140/90 mm $\mathrm{Hg}$ remains reasonable in adults younger than 80 years and of $150 \mathrm{~mm}$ $\mathrm{Hg}$ of systolic blood pressure in adults 80 years of age and older [6]. We should also be careful to avoid intensive lowering of the blood pressure in patients with hypertension, especially in those with diabetes and coronary artery disease, as this might be poorly tolerated and might increase cardiovascular events (the J-curve phenomenon).

\section{References}

1. Rosendorff C, Black HR, Cannon CP, Gersh BJ, Gore J, et al. (2007) Treatment of hypertension in the prevention and management of ischemic heart disease: a scientific statement from the American Heart Association Council for High Blood Pressure Research and the Councils on Clinical Cardiology and Epidemiology and Prevention. Circulation 115: 2761-2788.

2. Aronow WS (2011) Hypertension guidelines. Hypertension 58: 347-348

3. Bangalore S, Qin J, Sloan S, Murphy SA, Cannon CP (2010) What is the optima blood pressure in patients after acute coronary syndromes? Relationship of blood pressure and cardiovascular events in the Pravastatin or Atorvastatin Evaluation and Infection Therapy-Thrombolysis in Myocardial Infarction (PROVE IT-TIMI) 22 trial. Circulation 122: 2142-2151.

4. Cooper-DeHoff RM, Gong Y, Handberg EM, Bavry AA, Bakris GL, et al. (2010) Tight blood pressure control and cardiovascular outcomes among hypertensive patients with diabetes and coronary artery disease. JAMA 304: 61-68.

5. ACCORD Study Group, Cushman WC, Evans GW, Byington RP, Goff DC Jr, et al. (2010) Effects of intensive blood-pressure control in type 2 diabetes mellitus. N Engl J Med 362: 1575-1585.

6. Aronow WS, Fleg JL, Pepine CJ, et al. (2011) ACCF/AHA 2011 expert consensus document on hypertension in the elderly. J Am Coll Cardiol 57 2037-2114.

7. Beckett NS, Peters R, Fletcher AE, Staessen JA, Lisheng I, et al. (2008) Treatment of hypertension in patients 80 years of age or older. $\mathrm{N}$ Eng J Med 358: 1887-1898.

8. Banach M, Bhatia V, Feller MA, Mujib M, Desai RV, et al. (2011) Relation of baseline systolic blood pressure and long-term outcomes in ambulatory patients with chronic mild to moderate heart failure. Am J Cardiol 107: 1208-1214.

9. Mancia G, Schumacher H, Redon J, Verdicchia P, Jennings G, et al. (2011) Blood pressure targets recommended by guidelines and incidence of cardiovascular and renal events in the Ongoing Telmisartan Alone and in Combination With Ramipril Global Endpoint Trial (ONTARGET). Circulation 124: $1727-1736$

10. Guichard JL, Desai RV, Ahmed MI, Mujib M, Feller MA, et al. (2011) Isolated diastolic hypotension and incident heart failure in older adults. Hypertension 58: 895-901. 